\title{
Elective Central Compartment Neck Dissection for Papillary Thyroid Cancer-Hot Topics
}

\section{Gilberto Vaz Teixeira*}

Cepon, R. Presidente Coutinho, 579 Sala 304 Florianopolis, SC, Zip 88015-231, Brazil

\section{Introduction}

The American Thyroid Association (ATA) guidelines for differentiated thyroid cancer, published in 2006 and revised in 2009 [1] brought up some hot questions surrounding the emerging elective selective central compartment neck dissection procedure for Papillary Thyroid Cancer (PTC). Controversy exists regarding the indication of an elective surgical treatment for central compartment lymph nodes. The incidence of central compartment lymph node micro metastatic disease varies from $20 \%$ to $90 \%$ [2-5]. Some factors are associated with a higher risk of lymph node metastatic spread in PTC, including multifocal tumor [2], follicular variant of PTC, extra capsular extension, thyroiditis [6], male gender, tumor size, aggressive histologic type [7], MACIS score, lymph vascular invasion [8], over expression of D1 cyclin and galectin [9] and BRAF mutation [10]. The influence of lymph node metastasis on outcome in patients with PTC is widely known in the literature and determines a higher incidence of recurrence and decreases disease-free interval [11-13]. Otherwise the influence of micro metastatic disease on survival of patients harboring PTC is not well defined and maybe doesn't carry any risk. Beasley et al. [5], analyzing 522 patients with well differentiated thyroid cancer who presented neck node metastasis outside the central compartment, observed a 6-fold risk of developing recurrences, mostly in the neck, and disease-free and overall survival rates were significantly lower in these patients. Lundgren et al. [14] conducted a nested-case control study within the cohort of 5,123 patients diagnosed with Differentiated Thyroid Cancer (DTC) in Sweden between 1958-1987 and observed that approximately $36 \%$ of PTC patients were found to have locoregional spread. These cases with lymph node metastasis experienced a higher mortality rate (O.R. 2.5; 95\% C.I. 1.6-4.1). Zaydfudim et al. observed that for patients over 45 years-old, lymph node involvement was associated with a $46 \%$ increased risk of death [15]. The impact on disease free-interval and overall survival of micro metastatic lymph node disease comparing with macro metastatic disease seems to be different. The controversy is that a macro metastatic clinically evidenced disease starts as a micro metastatic lymph node implant. Continuously, almost $87 \%$ of thyroid cancers diagnosed in U.S. between 1988 and 2002 measured $2 \mathrm{~cm}$ or less [16]. This circumstance, lead us to suppose that for small tumors we probably will find small metastatic disease. The gene expression profile of a DTC tumor can be associated with an increased risk for Lymph Node (LN) metastasis [17] and the biological aggressiveness of some mutations can be found in small PTC as well. Rodolico et al. described that the presence of a BRAF mutation and p27 expression in PTC $\leq 1 \mathrm{~cm}$ is significantly associated with $\mathrm{LN}$ metastasis. In paired cases with the primary tumor and LN metastasis harboring the same mutation, they found a wider diameter of the largest metastatic area, a higher number of involved LNs and a higher percentage of metastatic lesions with extra capsular extension of LN [18]. This suggests that the potential aggressiveness of the tumor should be based on the tumor's biological profile, and not only on the primary tumor size.

The ATA 2009 revised guidelines [1] at the recommendation 27 states:“(b) Prophylactic central-compartment neck dissection (ipsilateral or bilateral) may be performed in patients with papillary thyroid carcinoma with clinically uninvolved central neck lymph nodes, especially for advanced primary tumors (T3 or T4). Recommendation rating: C. (c) Near-total or total thyroidectomy without prophylactic central neck dissection may be appropriate for small ( $\mathrm{T} 1$ or $\mathrm{T} 2$ ), noninvasive, clinically node-negative PTCs and most follicular cancer. Recommendation rating: C".

The rationale for these statements is based on the surgical expertise available and the decision to recommend a prophylactic Central Compartment Neck Dissection (CCND) has to consider the surgical team's experience. On experienced hands the elective (prophylactic) CCND carries almost the same rate of complications, except for temporary hypocalcaemia, where for every 7.7 CCNDs performed with thyroidectomy, there was one extra case of temporary hypocalcaemia when compared to thyroidectomy alone [19]. In literature, despite of the ATA recommendation for a selective indication for an elective CCND, we are observing an emerging number of studies, from different countries, showing good results with the use of an elective CCND for small and large PTCs [7,20-23]. When indicated, the use of an ipsilateral CCND, described according to the ATA consensus statement on the anatomy and terminology of central neck dissection [24], showed a high therapeutic efficacy with a low incidence of complications, when compared with the bilateral procedure [25].

Some authors advocate the indication of an elective CCND based on the issues that lymph node metastasis have a negative effect on patient outcome, cannot be reliably identified at operation, CCND can be performed safely at the first operation, allows a better staging of the disease, and reoperation for central neck recurrences has greater morbidity[26,27]. Others argue against these rationale based on the facts that this elective procedure can potentially increase the risk of operative complications mainly hyperparathyroidism and recurrent laryngeal nerve injury with resultant vocal cord palsy, for a nonaggressive disease; the majority of thyroidectomies are performed by low-volume surgeons; and the central compartment reoperation is a safe procedure when performed among experienced surgeons [28]. The emerging question is that in literature we have few studies showing the results of the central compartment reoperation surgery. The majority of them come from high-volume hospitals showing good results with their procedures [29-31]. Central compartment

*Corresponding author: Gilberto V Teixeira, Cepon, R. Presidente Coutinho, 579 Sala 304 Florianopolis, SC, Zip 88015-231, Brazil, Tel: +5504832247387; E-mail: gteixei1@gmail.com

Received November 21, 2012; Accepted November 23, 2012; Published November 28, 2012

Citation: Teixeira GV (2012) Elective Central Compartment Neck Dissection for Papillary Thyroid Cancer-Hot Topics. J Nucl Med Radiat Ther 3:e106. doi:10.4172/2155-9619.1000e106

Copyright: (c) 2012 Teixeira GV. This is an open-access article distributed under the terms of the Creative Commons Attribution License, which permits unrestricted use, distribution, and reproduction in any medium, provided the original author and source are credited. 
and thyroid bed reoperations are stressful, challenging and can cause unexpected complications sometimes life-threatening like pharyngeal or esophageal lesions. The other conflicting data is that when we analyze the clinical predictors associated with these reoperative cases, we can find a high number of primary tumors measuring less than $4 \mathrm{~cm}$. AlSaif et al. described their results with LN reoperation for persistent PTC where $93.8 \%$ of the patients had their primary tumors measuring less than $4 \mathrm{~cm}$ and $58.3 \%$ were submitted to CCND [32]. Clayman et al. analyzing 63 cases of CCND in patients with recurrent PTC observed $37 \%$ of patients with primary tumors measuring less than $4 \mathrm{~cm} \mathrm{[29].}$

For those who argue against elective CCND for small PTC (T1 and T2), one point is extremely debatable, based on the ATA recommendation 27 (c): “...central neck dissection may be appropriate for small (T1 or T2), noninvasive, clinically node-negative..." According to literature, the incidence of extra-thyroidal extension in PTC varies from $9 \%$ to $49 \%$ [12,33-35]. Analyzing the opposite point of view, the presence of an invasive extra-thyroidal extension determines the indication of a prophylactic approach to the central compartment nodes in $9 \%$ to $49 \%$ of the cases. Extra-thyroidal extension can be divided in two categories: minimal or massive extension. Ito and Miyauchi observed an incidence of massive extra-thyroidal extension in 13\% among 5,931 cases [13]. Kouvaraki et al. described the presence of extra-thyroidal extension as responsible for $33 \%$ of the reoperations in preventable reoperations for persistent and recurrent PTC, including completion thyroidectomy and lymph-node dissection [36]. Then, a preoperative or intra-operative finding of minimal or massive extrathyroidal extension precludes the indication for a prophylactic CCND. Extra-thyroidal extension is associated with a higher incidence of central compartment subclinical lymph node metastasis in a frequency ranging from $21 \%$ to $43 \%[20,21,37]$.

The concerning question about the presence of occult central compartment node metastasis in patients having a clinically evidenced lateral compartment node metastasis is emerging also. Roh et al. studied 22 cases of patients submitted to neck dissection for lateral nodal recurrence of PTC and were submitted to prophylactic CCND, observed an incidence of occult node metastasis in central compartment in $79 \%$ [38]. Machens et al. found skip metastases (negative central and positive lateral or mediastinal compartments) in only $13(20 \%)$ of 66 cases of PTC. Fifty-three (80\%) cases had a lateral compartment or mediastinal positive lymph node metastasis in conjunction with a central compartment node involvement [39]. Lee et al. described an incidence of occult lymph node metastasis in central compartment in $88 \%$ of their patients who had lateral LN metastasis [37].

Some other clinical and pathologic features are attributed to elevate the risk of central compartment node metastasis. Male gender, multifocality of the primary tumor, size over $0.5 \mathrm{~cm}$ and more aggressive histologic type (tall cell variant) are the most important factors $[3,7,21,37]$. These features are not enough to characterize a high risk profile for PTC [33], probably with a low impact in overall survival. By selecting a group of patients with high risk for central compartment node metastasis, we can define a more personalized treatment. This personalized approach will avoid over treatments for node metastasis low risk patients and will provide an adequate treatment for patients with an elevated incidence of central compartment node disease. It is common sense to carefully weigh the risks and benefits of an elective CCND before spreading this procedure widely. The benefit of this procedure in experienced hands supplants the low risk of definitive complications that is similar to a total thyroidectomy alone. Popadic et al. in a multicenter study observed that the group of patients submitted to an elective CCND, the stimulated thyroglobulin ( $\mathrm{Tg}$ ) values were lower before initial radioiodine ablation and there was a trend toward a lower $\mathrm{Tg}$ at the final follow-up in this group as well The rate of reoperation in the central compartment was lower in the elective CCND group [40].

In conclusion, since the revised version of the ATA guidelines in 2009, literature has been helping to find the risk group of patients for central compartment node metastasis. Patients with central compartment node metastasis have a high disease associated morbidity which provides a persistent elevated thyroglobulin, elevated risk for local and regional recurrences, risk for reoperations and these patients are frequently submitted to sequential doses of radioiodine ablation by clinicians. The diagnosis of a pre-operative or intra-operative extrathyroidal extension and a lateral neck compartment lymph node metastasis constitutes strong risk for occult lymph node metastasis, and adding an elective CCND seems reasonable. For male patients, over 45 years-old and with multifocal tumors diagnosed pre-operatively, the indication of an elective CCND can be based on the presence of two or more of these factors together For patients with primary tumor under $0.5 \mathrm{~cm}$ the risk of micro metastatic disease is very low and elective CCND is probably not justified in this scenario[7,37].

\section{References}

1. Cooper DS, Doherty GM, Haugen BR, Kloos RT, Lee SL, et al. (2009) Revised American Thyroid Association management guidelines for patients with thyroid nodules and differentiated thyroid cancer. Thyroid 19: 1167-1214.

2. Wada N, Duh QY, Sugino K, Iwasaki H, Kameyama K, et al. (2003) Lymph node metastasis from 259 papillary thyroid microcarcinomas: frequency, pattern of occurrence and recurrence, and optimal strategy for neck dissection. Ann Surg 237: 399-407.

3. Lim YC, Choi EC, Yoon YH, Kim EH, Koo BS (2009) Central lymph node metastases in unilateral papillary thyroid microcarcinoma. Br J Surg 96: 253257.

4. Roh JL, Park JY, Park CI (2007) Total thyroidectomy plus neck dissection in differentiated papillary thyroid carcinoma patients: pattern of nodal metastasis, morbidity, recurrence, and postoperative levels of serum parathyroid hormone. Ann Surg 245: 604-610.

5. Beasley NJ, Lee J, Eski S, Walfish P, Witterick I, et al. (2002) Impact of noda metastases on prognosis in patients with well-differentiated thyroid cancer. Arch Otolaryngol Head Neck Surg 128: 825-828.

6. Roti E, degli Uberti EC, Bondanelli M, Braverman LE (2008) Thyroid papillary microcarcinoma: a descriptive and meta-analysis study. Eur J Endocrinol 159 659-673.

7. Teixeira G, Teixeira T, Gubert F, Chikota H, Tufano R (2011) The incidence of central neck micrometastatic disease in patients with papillary thyroid cancer staged preoperatively and intraoperatively as N0. Surgery 150: 1161-1167.

8. Koo BS, Choi EC, Yoon YH, Kim DH, Kim EH, et al. (2009) Predictive factors for ipsilateral or contralateral central lymph node metastasis in unilateral papillary thyroid carcinoma. Ann Surg 249: 840-844.

9. Londero SC, Godballe C, Krogdahl A, Bastholt L, Specht L, et al. (2008) Papillary microcarcinoma of the thyroid gland: is the immunohistochemical expression of cyclin D1 or galectin-3 in primary tumour an indicator of metastatic disease? Acta Oncol 47: 451-457.

10. Xing M (2007) BRAF mutation in papillary thyroid cancer: pathogenic role molecular bases, and clinical implications. Endocr Rev 28: 742-762.

11. Gemsenjäger E, Perren A, Seifert B, Schüler G, Schweizer I, et al. (2003) Lymph node surgery in papillary thyroid carcinoma. J Am Coll Surg 197: 182 190.

12. Leboulleux S, Rubino C, Baudin E, Caillou B, Hartl DM, et al. (2005) Prognostic factors for persistent or recurrent disease of papillary thyroid carcinoma with neck lymph node metastases and/or tumor extension beyond the thyroid capsule at initial diagnosis. J Clin Endocrinol Metab 90: 5723-5729.

13. Ito Y, Miyauchi A (2009) Prognostic factors and therapeutic strategies for differentiated carcinomas of the thyroid. Endocr J 56: 177-192. 
Citation: Teixeira GV (2012) Elective Central Compartment Neck Dissection for Papillary Thyroid Cancer-Hot Topics. J Nucl Med Radiat Ther 3:e106. doi:10.4172/2155-9619.1000e106

Page 3 of 3

14. Lundgren $\mathrm{Cl}$, Hall $\mathrm{P}$, Dickman PW, Zedenius J (2006) Clinically significant prognostic factors for differentiated thyroid carcinoma: a population-based, nested case-control study. Cancer 106: 524-531.

15. Zaydfudim V, Feurer ID, Griffin MR, Phay JE (2008) The impact of lymph node involvement on survival in patients with papillary and follicular thyroid carcinoma. Surgery 144: 1070-1077.

16. Davies L, Welch HG (2006) Increasing incidence of thyroid cancer in the United States, 1973-2002. JAMA 295: 2164-2167.

17. Oler G, Camacho CP, Hojaij FC, Michaluart P, Riggins GJ, et al. (2008) Gene expression profiling of papillary thyroid carcinoma identifies transcripts correlated with BRAF mutational status and lymph node metastasis. Clin Cancer Res 14: 4735-4742.

18. Rodolico V, Cabibi D, Pizzolanti G, Richiusa P, Gebbia N, et al. (2007) BRAF V600E mutation and p27 kip1 expression in papillary carcinomas of the thyroid $<0 r=1 \mathrm{~cm}$ and their paired lymph node metastases. Cancer 110: 12181226.

19. Chisholm EJ, Kulinskaya E, Tolley NS (2009) Systematic review and metaanalysis of the adverse effects of thyroidectomy combined with central neck dissection as compared with thyroidectomy alone. Laryngoscope 119: 11351139.

20. Bonnet S, Hartl D, Leboulleux S, Baudin E, Lumbroso JD, et al. (2009) Prophylactic lymph node dissection for papillary thyroid cancer less than $2 \mathrm{~cm}$ : implications for radioiodine treatment. J Clin Endocrinol Metab 94: 1162-1167.

21. So YK, Son YI, Hong SD, Seo MY, Baek CH, et al. (2010) Subclinical lymph node metastasis in papillary thyroid microcarcinoma: a study of 551 resections. Surgery 148: 526-531.

22. Ito $\mathrm{Y}$, Masuoka $H$, Fukushima $M$, Inoue $H$, Kihara $M$, et al. (2010) Excellent prognosis of patients with solitary T1NOMO papillary thyroid carcinoma who underwent thyroidectomy and elective lymph node dissection without radioiodine therapy. World J Surg 34: 1285-1290.

23. Shindo M, Stern A (2010) Total thyroidectomy with and without selective central compartment dissection: a comparison of complication rates. Arch Otolaryngol Head Neck Surg 136: 584-587.

24. American Thyroid Association Surgery Working Group; American Association of Endocrine Surgeons,; American Academy of Otolaryngology-Head and Neck Surgery; American Head and Neck Society, Carty SE, Cooper DS, Doherty GM, et al. (2009) Consensus statement on the terminology and classification of central neck dissection for thyroid cancer. Thyroid 19: 1153-1158.

25. Lee YS, Kim SW, Kim SW, Kim SK, Kang HS, et al. (2007) Extent of routine central lymph node dissection with small papillary thyroid carcinoma. World $J$ Surg 31: 1954-1959.

26. Mazzaferri EL, Doherty GM, Steward DL (2009) The pros and cons of prophylactic central compartment lymph node dissection for papillary thyroid carcinoma. Thyroid 19: 683-689.

27. Shindo M, Wu JC, Park EE, Tanzella F (2006) The importance of centra compartment elective lymph node excision in the staging and treatment of papillary thyroid cancer. Arch Otolaryngol Head Neck Surg 132: 650-654.

28. Carling T, Long WD 3rd, Udelsman R (2010) Controversy surrounding the role for routine central lymph node dissection for differentiated thyroid cancer. Curr Opin Oncol 22: 30-34.

29. Clayman GL, Shellenberger TD, Ginsberg LE, Edeiken BS, El-Naggar AK et al. (2009) Approach and safety of comprehensive central compartment dissection in patients with recurrent papillary thyroid carcinoma. Head Neck 31: 1152-1163

30. Tufano RP, Bishop J, Wu G (2012) Reoperative central compartment dissection for patients with recurrent/persistent papillary thyroid cancer: efficacy, safety, and the association of the BRAF mutation. Laryngoscope 122: 1634-1640.

31. Schuff KG, Weber SM, Givi B, Samuels MH, Andersen PE, et al. (2008) Efficacy of nodal dissection for treatment of persistent/recurrent papillary thyroid cancer. Laryngoscope 118: 768-775.

32. Al-Saif O, Farrar WB, Bloomston M, Porter K, Ringel MD, et al. (2010) Long term efficacy of lymph node reoperation for persistent papillary thyroid cancer. $\mathrm{J}$ Clin Endocrinol Metab 95: 2187-2194.

33. Shaha AR (2004) Implications of prognostic factors and risk groups in the management of differentiated thyroid cancer. Laryngoscope 114: 393-402.

34. Zuniga S, Sanabria A (2009) Prophylactic central neck dissection in stage NO papillary thyroid carcinoma. Arch Otolaryngol Head Neck Surg 135: 1087-1091.

35. Forest VI, Clark JR, Ebrahimi A, Cho EA, Sneddon L, et al. (2011) Central compartment dissection in thyroid papillary carcinoma. Ann Surg 253: 123-130.

36. Kouvaraki MA, Lee JE, Shapiro SE, Sherman SI, Evans DB (2004) Preventable reoperations for persistent and recurrent papillary thyroid carcinoma. Surgery 136: $1183-1191$

37. Lee SH, Lee SS, Jin SM, Kim JH, Rho YS (2008) Predictive factors for centra compartment lymph node metastasis in thyroid papillary microcarcinoma. Laryngoscope 118: 659-662.

38. Roh JL, Park JY, Rha KS, Park Cl (2007) Is central neck dissection necessary for the treatment of lateral cervical nodal recurrence of papillary thyroid carcinoma? Head Neck 29: 901-906.

39. Machens A, Holzhausen HJ, Dralle H (2004) Skip metastases in thyroid cancer leaping the central lymph node compartment. Arch Surg 139: 43-45.

40. Popadich A, Levin O, Lee JC, Smooke-Praw S, Ro K, et al. (2011) A multicente cohort study of total thyroidectomy and routine central lymph node dissection for cN0 papillary thyroid cancer. Surgery 150: 1048-1057. 